\title{
THREE COMPLETE PLANT-POLLINATOR NETWORKS ALONG A SECONDARY SUCCESSIONAL GRADIENT IN CRITICALLY ENDANGERED RENOSTERVELD, SOUTH AFRICA
}

\author{
OS Cowan*1 and PML Anderson² \\ IDepartment of Environmental and Geographical Sciences, University of Cape Town, South Africa \\ ${ }_{2}^{2}$ African Centre for Cities, Department of Environmental and Geographical Sciences, University of Cape Town, South Africa
}

\begin{abstract}
Despite the global recognition of the importance of pollination as an ecosystem function, there remains a dearth of community level studies on the African continent. Here we present three complete pollination networks, along a secondary successional gradient, in critically endangered Renosterveld vegetation within an agri-environment, South Africa. Site selection was based on historical land-use and contemporary vegetation data resulting in a pristine site, a late successional site where agriculture was halted > I5 years ago, and an early successional site where agriculture was halted <five years ago. In total, 240 hours of pollinator-plant observations were recorded over a single flowering season. The pristine site was highly specialised in comparison to global datasets - most likely as a result of relative climatic stability through the Quaternary which allowed specialisation to manifest and persist. Both non-pristine sites showed noticeable differences in characteristics when expressed through network indices; however, the early successional site was closer in nature to the pristine site as a result of vegetation structure. Notwithstanding a lack of replication across the successional gradient precluding robust statistical analyses, this study provides important data which allows for the comparison of pollination dynamics in an understudied and vulnerable vegetation type, to plantpollinator networks at the global and regional scale. In addition, apparent changes to network indices as a result of habitat alteration, suggest that successional trajectory plays an important role in pollination dynamics.
\end{abstract}

Keywords: Pollination, Food-Webs, Ecosystem Functioning, Specialization, Agri-Ecosystems

\section{INTRODUCTION}

Global insect populations are in peril due in part to intensive agriculture and habitat change (Sanchez-Bayo \& Wyckhuys 2019). The potentially catastrophic effects on key ecosystem functions such as pollination (Kevan \& Viana 2003; Brown \& Paxton 2009; Potts et al. 2010) will not only have dire ecological implications (Vanbergen et al., 20I3) but huge economic consequences (Costanza et al. 1997; Gallai et al. 2009). Yet the drivers influencing insect populations and pollination that relate to habitat change are poorly understood at the community and landscape level (Hallmann et al. 20I7; Redhead et al., 2018), and in many instances, particularly on the African continent, remain undescribed (Vizenti-Bugani et al. 2018).

Fuelled largely by developments in complex network analysis (Proulx et al. 2005), an increasingly popular way of assessing pollination functioning is through pollination network analysis (Bascompte 2009; Vizentin-Bugoni et al. 2018). Community pollination networks can be defined both visually, in the form of quantitative flower visitation webs, and numerically through indices which describe network properties (Dormann et al. 2009). Pollination networks

Received 23 February 20I I, accepted 28 June 201 I

*Corresponding author: cwnoli001@gmail.com across diverse habitats, species assemblages, and time have shown similar structural properties (Jordano et al. 2003; Vazquez et al. 2009). Networks tend to exhibit low connectance (i.e. only a small fraction of possible interactions are observed), are nested (i.e. specialist species predominantly interact with a core group of generalist species), and species are significantly more specialized than expected given the availability of potential mutualistic partners (Jordano et al. 2003; Bluthgen et al. 2008; Dupont et al. 2009). Indices calculated from qualitative interactions, while useful (Jordano 1987), tend to be less sensitive to change than quantitative indices which take into account the frequency of pollinatorplant interaction and thus are better suited for revealing smallscale changes to network structure and are more robust to sampling effects (Bluthgen et al. 2008; Almeida-Neto \& Ulrich 20I I). Despite a need for caution when using network indices to interpret biologically meaningful patterns due to the effect sampling limitations can impart on analyses (Blüthgen 2010; Chacoff et al. 2012), pollination network analysis has been successfully used to identify and assess factors influencing biodiversity maintenance (Bascompte et al. 2006 Albrecht et al. 2010; Valdovinos et al. 2013), to predict consequences of disturbances such as extinction (Memmott et al. 2004; Kaiser-Bunbury et al. 2010; Saavedra et al. 20I I), inform the restoration of degraded ecosystems (Menz et al. 20II; Kaiser-Bunbury et al. 2017), and establish the impact alien species have in disturbed ecosystems (Bartomeus et al. 2008; Valdovinos et al. 2009). 
Abandonment of agricultural land for economic or ecological reasons is common practice in contemporary times (Villa-Galaviz et al. 20I2). During the secondary succession which follows, environmental variability along the successional gradient influences pollinator population dynamics (Steffan-Dewenter \& Tscharntke 200I) and plant community structure (Garnier et al. 2004); however the subsequent changes in interaction networks at the community level, such as pollination, are poorly understood (Albrecht et al. 2010) and may be affected by land-use history and ecological drivers post-abandonment such as fire regime (Potts et al. 2003; Brown et al. 2017) or grazing intensity (Vanbergen et al. 20I4). A change in habitat can alter the structure of pollination networks, and thus network indices, through changes in species richness and the functional composition of the community (Tylianakis et al. 2007). For example, higher values of nestedness reflect the prevalence of specialist species that predominantly interact with a core group of generalist species (Grass et al. 2018). However, nestedness changes with the number of interacting species e.g. a loss of rare species which interact with abundant generalists would reduce nestedness (Spiesman \& Inouye 2013). Shifts in functional composition, such as floral size thresholds (Stang et al. 2009), may further modify community nestedness as the number of possible interactions are altered (Vazquez et al. 2009). Similarly, specialization indices may change following the removal or influx of certain species. For example, homogenization of above-ground vegetation alters the spectrum of resources available to pollinators which may lead to local extinction or re-wiring of the network (KaiserBunbury et al. 2010; CaraDonna et al. 2017). It is clear that any shifts in the number of interacting species or the functional composition of a community caused by habitat alteration, either through natural succession, restoration or habitat disturbance, can have cascading effects on network structure and ecosystem functioning (Albrecht et al. 2010; Ferreira et al. 2013; Vanbergen et al. 2014; Ponisio et al. 2017). Understanding how these shifts occur and what impact they have on network properties can provide important information towards understanding the underlying ecological processes (MacFadyen et al. 2009; Vanbergen et al. 2017) and is a powerful tool in conservation (Devoto et al. 2012; KaizerBunbury \& Bluthgen 20I5).

Renosterveld is an ecologically distinct vegetation type within the Cape Floristic Region of South Africa (Bergh et al. 2014). Only $10 \%$ of the original extent remains due to intensive agricultural conversion (Newton \& Knight 2005) with critical endangered remnant fragments of natural vegetation found embedded within an agricultural matrix (Kemper et al. I999). Differences in historical land-use and current management practices has resulted in patches of natural vegetation occurring side-by-side along somewhat of a degradation gradient from pristine vegetation to old fields in various stages of secondary succession (Heelemann et al. 2013; Cowan \& Anderson 2014; Ruwanza 2017). The ecological workings of Renosterveld remain understudied (Curtis 2013) and there is a dearth of community-level pollination network analyses and pollination studies in general (but see Donaldson et al. 2002; Pauw 2007; Kehinde \& Samways 20I4; Pauw \& Hawkins 20I I). To our knowledge, only one comprehensive study exists from neighbouring pristine Fynbos (Pauw \& Stanway 2015). Notably, Pauw and Stanway (2015) reported globally unrivalled functional specialization in their study, attributing it to the long-term climatic stability in the region which they argue allowed phenotypic and functional specialization to manifest and persist. Renosterveld has similar floral diversity levels to that of Fynbos (Bergh et al. 2014) but due to its comparatively fertile underlying soils has undergone significantly greater agricultural transformation (Kemper et al. 1999) with the significance of this transformation largely untested on ecological functioning.

Here, for the first time, we present three fully quantitative pollination networks along a successional gradient from recently abandoned agricultural land to pristine Renosterveld and ask the following questions. (I) What are the characteristics of these plant-pollinator networks when expressed through network indices?, (2) Are the indices of the studied networks similar to the indices of a published pollination network in adjacent Fynbos vegetation?, (3) How do the indices of the studied networks compare to the indices of pollination networks published globally?, (4) How is the degree of habitat alteration as a result of successional vegetation shifts related to (a) the richness, evenness and diversity of species and interactions?, and (b) the degree of interaction network-level, and species-level, specialization?

\section{MATERIALS AND METHODS}

Study area, site selection and vegetation characteristics

Haarwegskloof Nature Reserve (34²0'17.9”'S; $20^{\circ}$ I9'34.I”E) is situated within the Overberg lowlands of the Western Cape Province of South Africa (Fig. I). Renosterveld, the indigenous vegetation of the Overberg region, is classified as critically endangered (Rebelo et al. 2006) with less than $10 \%$ of the original extent remaining (Curtis 2013). The vegetation type exists as fragmented islands within an agricultural matrix of privately owned land (Kemper et al. 1999) and the cover is predominantly grain fields (wheat, barley, oats, canola) and artificial pasture (lucerne/alfalfa) (Curtis et al. 2013).

The reserve itself is situated within the Eastern Rûens Shale Renosterveld and was purchased by the WWF-SA and the Overberg Renosterveld Conservation Trust in 2013. It consists of approximately 500 hectares of land, purportedly $80 \%$ of which is virgin Renosterveld while the remaining area is old lands of varying age, portions of which may have been previously ploughed and/or used as grazing pasture. Eastern Rûens Shale Renosterveld has an altitudinal range of 40-320 m.a.s.l. and an average rainfall of $384 \mathrm{~mm}$ per annum with an essentially even distribution (Rebelo et al. 2006; Curtis et al. 2013). Mean daily temperatures range from a $5.9^{\circ} \mathrm{C}$ minimum in July to a $26.9^{\circ} \mathrm{C}$ maximum in January (Rebelo et al. 2006). Natural Eastern Rûens Shale Renosterveld occurs on moderately undulating hills and plains which support a cupressoid and small-leaved, low to moderately high grassy shrubland (Rebelo et al. 2006). 

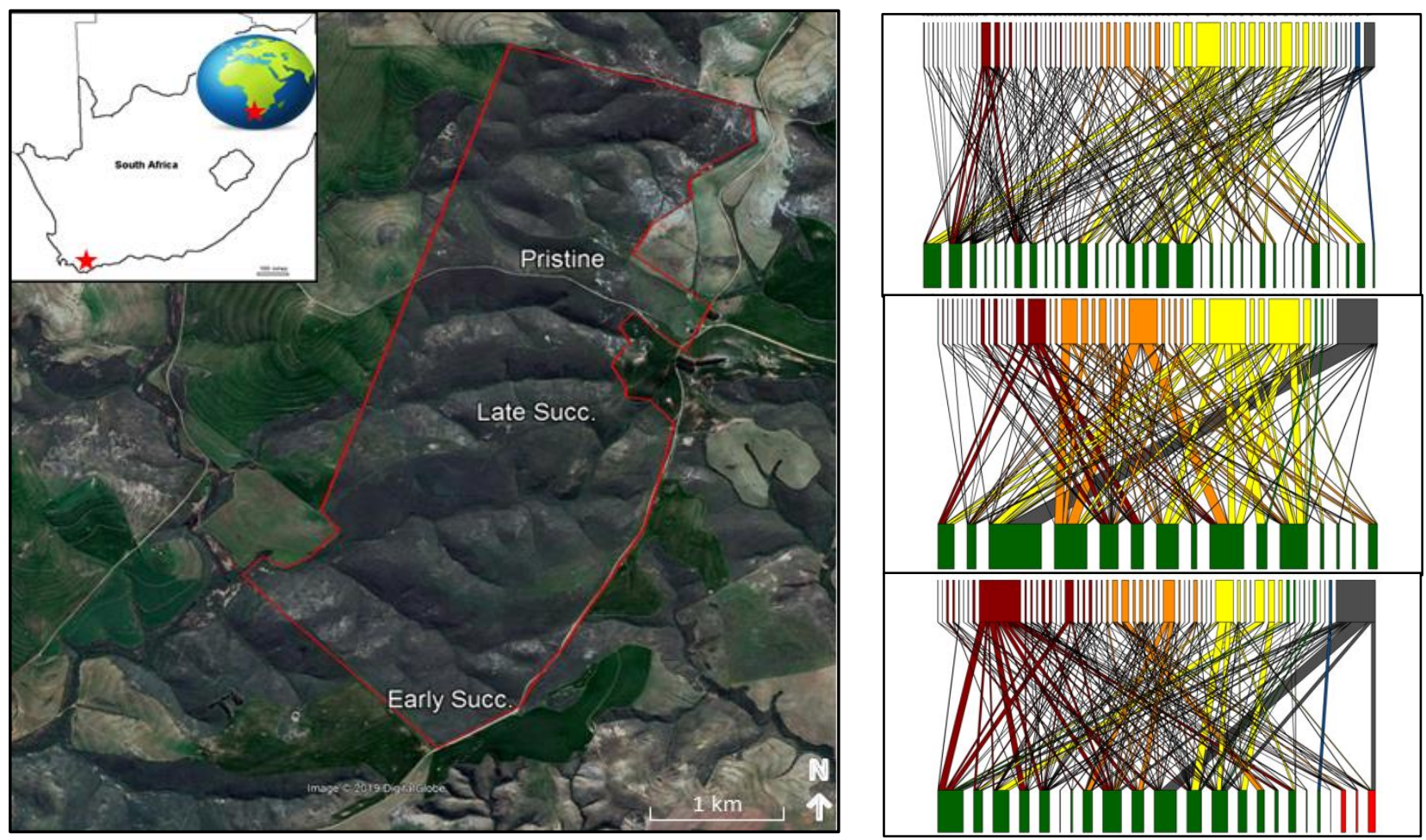

FIGURE I: Study area showing the three study sites within Haarwegskloof Reserve (red polygon) and their associated quantitative plantpollinator networks. Late Succ. refers to the late successional site and Early Succ. refers to the early successional site. Pollinators are shown as rectangles at the top (Red=Coleoptera, Orange=Diptera, Yellow $=$ Hymenoptera, Green=Lepidoptera, Blue=Avis, Grey=Thysanoptera) and plants as rectangles at the bottom (red rectangles depict alien plant species). Detailed networks with species names are supplied in Appendix A.

Historical aerial photograph analysis, combined with expert local knowledge, was utilised to select three sites situated along a historic successional gradient: pristine vegetation, a site where agriculture ceased approximately I5 years ago, and a site where agricultural activities ceased less than five years ago. At each site vegetation sampling and abundance was conducted using the modified Whittaker nested vegetation sampling method (Stohlgren et al. 1995). With the aid of expert knowledge and herbarium records over $80 \%$ of the species encountered were identified to species level and over $90 \%$ to genus level. Thus we worked in three study sites of $1000 \mathrm{~m}^{2}$ : Pristine - characterised by high species richness, the absence of alien species and no evidence of historical agriculture; Late Successional - characterised by moderate to low diversity, dominance of shrub species and evidence of historical agricultural use; and Early Successional - characterized by moderate to low diversity, high alien species cover and evidence of recent agricultural use. The late successional site was situated I km from the pristine site with the early successional site a further $1.8 \mathrm{~km}$ away. Each study site had a buffer zone $(>250 \mathrm{~m})$ of vegetation of similar composition and structure to the site in question with the exception of the early successional site which was abutted by a wheat field on one side.

Using the literature, each plant species recorded during sampling was assigned a growth form under the categories: Hemiparasite; Semi Basal; Short Basal; Short Succulent; Climbers and Scramblers; Tussock; Erect Leafy; Dwarf Shrub $(<0.8 \mathrm{~m})$; Shrub $(>0.8 \mathrm{~m})$; Trees (sensu Cornelissen et al. 2007). While no causal relationship is inferred in this study between growth form and pollination, the data was used to assess differences in vegetation structure between sites which in turn can affect pollinator communities (Ferreira et al 2013).

Each plant species had its flower colour assigned to one of seven categories based on direct observation: Red; Orange; Green/Yellow/Cream; Rose; Yellow; White; Blue/Purple/Lilac. Where flowers consisted of more than one category the dominant category was chosen. The exact role of flower colour, particularly how it is perceived by humans and its relative importance to different pollinator guilds, has been debated in pollination biology (Vorobyev \& Brandt 1997; Arnold et al. 2009; Bukovac et al. 2017); however here we use it as an accessory to assess differences in vegetation structure and characteristic between study sites and no further assumptions are made on its impact on pollinator communities.

\section{Pollinator observations}

Pollinator-plant interaction observations were undertaken during the austral spring (August-November) of 2016, the peak flowering season in Renosterveld, with methods adapted from Pauw and Stanway (2015). Observations were carried out during clear, warm, relatively wind-free days between $8 \mathrm{am}$ and $5 \mathrm{pm}$ during the first two weeks of August, September, October and November. Flowering plant species were initially selected at random and observed in 30-minute periods. Subsequently, species were selected so that each species at each site was observed at least twice during a morning observation session (8-I2am) and twice in an afternoon observation session ( $12-5 \mathrm{pm})$ for a minimum total observation period of 
2 hrs per species per site. All three sites were observed during each two-week block, alternating each site between morning and afternoon observation periods to ensure equal coverage (approximately four morning and four afternoon sessions at each site per two week block). In total 240 hours of observations were recorded across all three sites. On some occasions, plant species occurring close together were observed simultaneously. Observations typically occurred from between two and five metres away from the plant(s) whereas birds were observed from a distance of $>10 \mathrm{~m}$ with the use of binoculars. During each observation period, flower visitors were identified and each individual flower visit recorded. Where possible, only visitors that made contact with flower reproductive organs were recorded and composite inflorescences were treated as single flowers. Pollination activity was expressed as visits flower-1 hour. At the first observation of an unidentified pollinator species, the insect was caught and included in a reference collection to aid species identification. Whenever possible, pollinators were caught outside of the observation period. Pollinators were killed humanely, stored in ethanol, and identified to lowest taxonomic level possible using the collections at the South African Museum, Cape Town.

Similarly to Pauw and Stanway (2015), we took a plantcentric approach where each flowering plant present received equal sampling effort rather than a "representative" transect approach which would have under-sampled species due to the heterogeneous landscape (Gibson et al. 20II).

\section{Data analysis}

Plant growth form and flower colour data were used in conjunction with vegetation cover data to construct figures illustrating a) the proportional cover of growth forms at each site and $b$ ) the proportion of flower colours present in springflowering species at each site. Quantitative pollination networks were illustrated as bipartite visitation graphs using matrices of visitation rates for every plant species from each study site. Two rows of rectangles representing pollinator and plant species are connected by lines, with a thickness proportional to the interaction strength. The presence of individual species (both plants and pollinators) at each site were used to calculate the proportion of species occurring in all three sites, shared between two sites, and found solely in a single site.

The following qualitative network parameters were calculated for each network: Number of plant species ( $p)$, number of pollinators $(\mathrm{a})$, species richness $(\mathrm{r}=\mathrm{p}+\mathrm{a})$, network size $\left(s=p^{*} a\right)$, total number of interactions recorded (i), connectance $(c=i / s)$ : the realized proportion of possible links (Blüthgen et al. 2006), web asymmetry ( $w=(p-$ a) $/(p+a))$ : the balance between pollinator and plant numbers, mean number of links per pollinator, and mean number of links per plant. Although these indices by and large provide an indication of the size of the networks, they can allow for basic comparisons between network characteristics not only within this study but from other pollination network studies.

In addition, we computed the following quantitative indices which take into account the magnitude of the interaction and were based on the Shannon measure of
Entropy H: WeightedNODF - a quantitative value for nestedness where higher values indicate increased nestedness (Almeida-Neto \& Ulrich 20II), weighted connectance linkage density divided by number of species in the network (Tylianakis et al. 2007), interaction evenness - homogeneity of interaction frequencies across all links in the network, with higher values reflecting a more uniform spread of interaction among the species in the community (Tylianakis et al. 2007), Interaction Diversity - Shannon's diversity of interactions, $\mathrm{H}_{2}$ ' - a network level of specialisation where 0 equates to no specialisation and I complete specialisation (Blüthgen et al. 2006). To detect whether the observed results were due to ecological mechanisms rather than sampling artefacts, observed values were compared to those generated by a null model. For each network of study, I000 randomly generated matrices of the same size were created using the $\mathrm{r} 2 \mathrm{~d}$ method. Standardized $\mathrm{z}$-scores were calculated for each metric $(\mathrm{z}=$ [observed - null mean]/null $\sigma$ ) to test for significant differences.

The lack of replication of site type prevents any statistical comparison of network-level indices, thus our interpretations are merely descriptive; however they do allow for discussion on the effect of land-use history and contemporary vegetation dynamics on the richness, evenness, diversity and specialization observed in plant-pollinator interactions while providing a means of comparison between this and other similar studies and a baseline for future work.

Statistical analysis could be, and was, performed on species-level specialization. The Kullback-Leibler distance (d') expresses how strongly a species deviates from interacting with species in proportion to its overall importance in the community (Bluthgen et al. 2006). Values range from 0 (no specialization) to I (complete specialization). Additionally, mean number of links per species for both plants and pollinators were calculated. One-way ANOVAs and Tukey Multiple Pairwise Comparisons (normally distributed data) and Kruskall-Wallis and pairwise comparisons using Wilcoxon rank sums (not normal data) tests were combined to test for significant differences between the aforementioned indices for species (both plant and pollinator) occurring in all three sites and for pollinator groups (e.g. Hymenoptera, Diptera etc.) between sites.

All analysis was conducted with the statistical package BIPARTITE in R (Dormann et al. 2018; R Core Team 2013).

\section{RESULTS}

\section{Ecological Composition}

In total 62 flowering plant species were observed across the three sites however there were no recorded visitors for II of these species. Of the $5 \mathrm{I}$ species which were present in the pollination web analyses only six species (I2\%) were found in all three study sites with a further II (22\%) occurring in two of the three sites. Most species - 34 (66\%) - were found in one site only of which 24 were found solely in the pristine site (Fig 2A). Species and family richness were higher in the pristine site compared to the late and early successional sites; however, the early successional site, supplemented by 


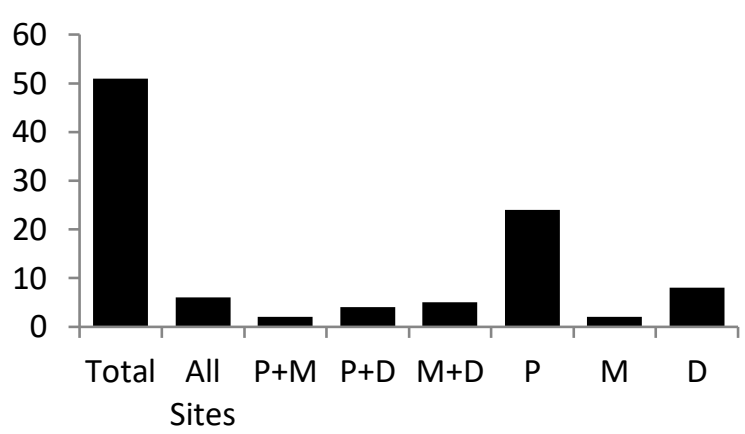

A

Site where found

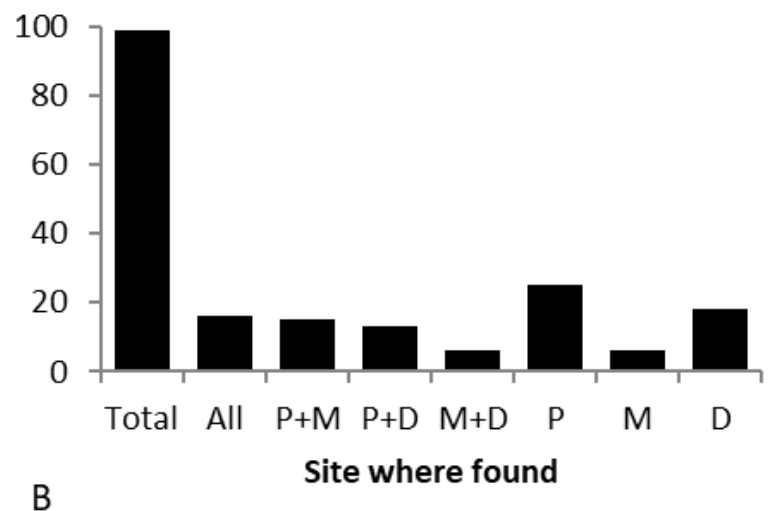

FIGURE 2: The number of (A) plant species, and (B) pollinator species found in total and in common across the three sites. $\mathrm{P}=$ Pristine; $\mathrm{M}=$ Late Successional; $\mathrm{D}=$ Early Successional.

increased alien species numbers, was more diverse than the late successional site. With respect to alien plant species, none were recorded in the pristine site while the three flowering species of aliens in the late successional site were not observed receiving visitors. In the early successional site only one out of the five flowering alien species did not receive visitors ( $\mathrm{Tab}$. IA).

A total of 99 pollinator species were observed across the three sites. Coleptera $(43 \%)$ was the most diverse order followed by Diptera (24\%), Hymenoptera (19\%) and
Lepidoptera (10\%). In terms of total pollinator species recorded, numbers mirrored those observed for plant species with the most recorded in the pristine site and the least in the late successional site. Proportionally, the number of Coleoptera species remained fairly constant ( $\sim 40 \%$ of total species), however the pristine site had a lower proportion of recorded Diptera species (23\%) compared with the early successional site (Diptera: 29\%) which, in turn, had fewer than the late successional site (Diptera: 35\%). There was a noticeably higher proportion of Hymenoptera species recorded in the pristine site (25\% of species recorded) while the highest proportion of Lepidoptera was found in the early successional site (I5\% of species recorded). No bird pollination was observed in the late successional site despite the presence of a bird-pollinated plant species (Tab. IB). Of the 99 pollinator species recorded, only 16 were observed across all three sites with 25 solely recorded in the pristine site, and six and 18 observed exclusively in the late and early successional sites respectively (Fig. 2B).

In all three sites yellow was the dominant flower colour present. While all seven flower colour categories were represented in the pristine and early successional sites, only red, yellow, white and blue flowers were present in the late successional site (Fig. 3A).

In terms of vegetation structure, the overall communities of both pristine and late successional sites were dominated by shrubs $(75 \%$ and $85 \%$, respectively) whereas the early successional site had only $40 \%$ shrub cover with a higher cover of herbaceous basal (25\%) and tussock (20\%) species. Diversity of plant growth forms was greatest in the pristine site (II) compared to the late and early successional sites (seven and eight growth forms, respectively) (Fig. 3B).

\section{Network Analyses}

The pollination networks show visible differences between study sites (Appendix i). In the early successional site $36 \%$ of all recorded interactions were from Coleoptera, double the proportion recorded elsewhere. Diptera accounted for $30 \%$ of interactions in the late successional site, markedly higher than the early successional (20\%) and pristine (16\%)

TABLE I: $\quad$ A) Floral, and B) Pollinator composition of the three study sites.

\begin{tabular}{|c|c|c|c|c|c|c|c|}
\hline A) Plants & Pristine & $\begin{array}{l}\text { Late } \\
\text { Successional }\end{array}$ & $\begin{array}{l}\text { Early } \\
\text { Successional }\end{array}$ & B) Pollinators & Pristine & $\begin{array}{l}\text { Late } \\
\text { Successional }\end{array}$ & $\begin{array}{l}\text { Early } \\
\text { Successional }\end{array}$ \\
\hline Total Species & 56 & 28 & 36 & Total Species & 69 & 43 & 53 \\
\hline Total Families & 27 & II & $\mathrm{I} 2$ & Coleoptera & 29 & 17 & $2 \mathrm{I}$ \\
\hline $\begin{array}{l}\text { Total Alien Species } \\
\text { (Flowering) }\end{array}$ & $\mathrm{O}(0)$ & $3(0)$ & $\mathrm{IO}(5)$ & Diptera & 16 & 15 & 15 \\
\hline $\begin{array}{l}\text { Spring Flowering } \\
\text { Species }\end{array}$ & 43 & 22 & 27 & Hymenoptera & 17 & 6 & 7 \\
\hline $\begin{array}{l}\text { Spring Flowering } \\
\text { Families }\end{array}$ & $2 \mathrm{I}$ & 8 & 9 & Lepidoptera & 5 & 4 & 8 \\
\hline $\begin{array}{l}\text { Spring Flowering } \\
\text { Cover }(\%)\end{array}$ & 80 & 50 & 70 & Avians & I & 0 & I \\
\hline $\begin{array}{l}\text { Flowering Species } \\
\text { With No Visits }\end{array}$ & 7 & 7 & 4 & Thysanoptera & $\mathrm{I}$ & I & I \\
\hline
\end{tabular}




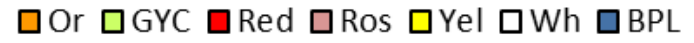
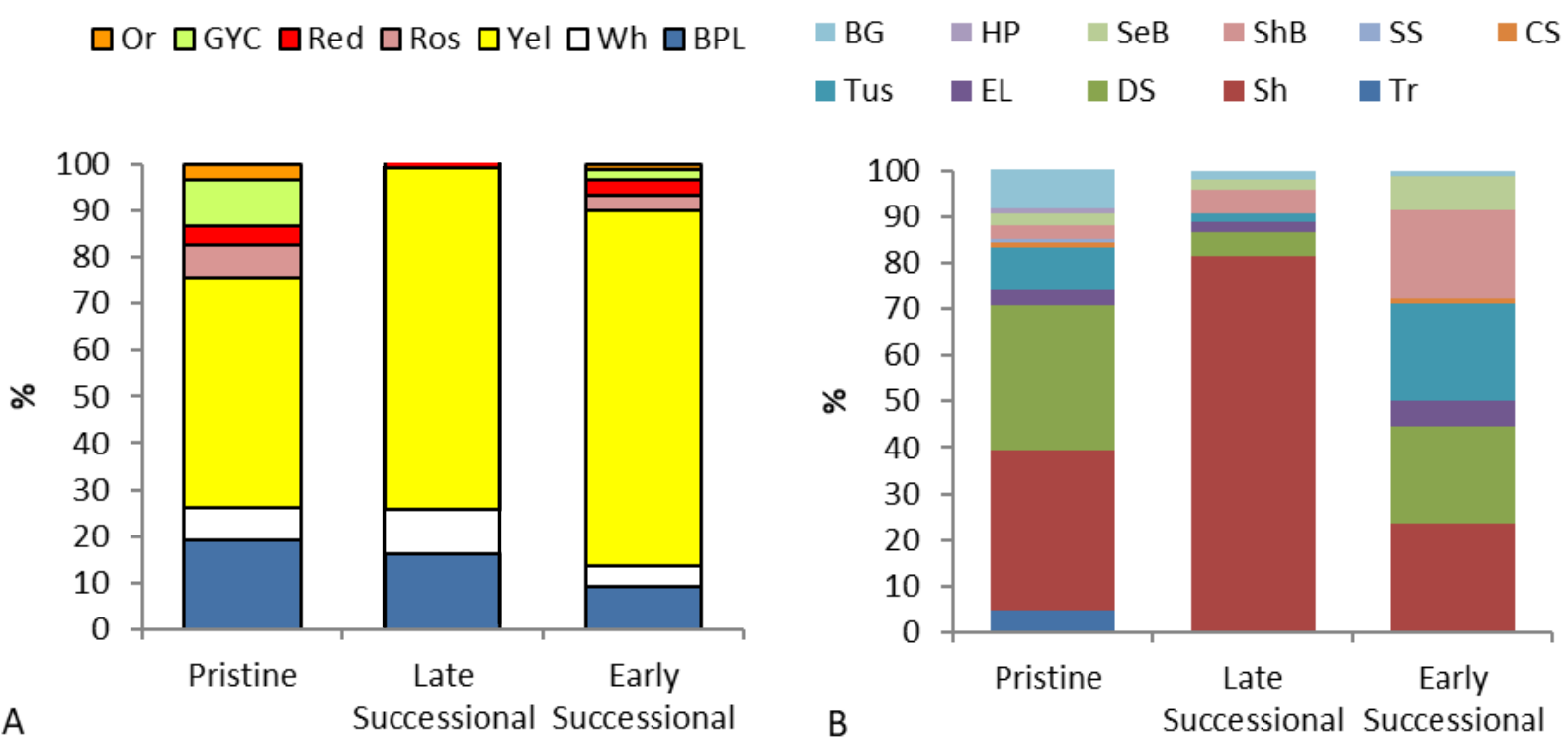

FIgure 3: A) Proportion of Flower Colours of the Spring Flowering Plant Cover across the three study sites, and B) Proportion of plant growth forms across the three study sites. (Or-Orange; GYC-green/yellow/cream; Ros-Rose; Yel-Yellow; Wh-White; BPL-Blue/Purple/Lilac). (BG-Bare Ground; HP-Hemiparasites; SeB-Semi Basal; ShB-Short Basal; SS-Short Succulent; CS-Climbers \& Scramblers; Tus-Tussock; EL-Erect Leafy; DSDwarf Shrub (<0.8m); Sh-Shrub ( $>0.8 \mathrm{~m})$; Tr-Trees (sensu Cornelissen et al 2007).

TABLE 2: Qualitative pollination network indices for the three study sites

\begin{tabular}{lrrr}
\hline & Pristine & Late Successional & Early Successional \\
\hline Number of Plant Species (P) & 36 & 15 & 23 \\
Number of Pollinator Species (A) & 69 & 43 & 55 \\
Species Richness (R) & 105 & 58 & 78 \\
Network Size (S) & 2484 & 645 & 1265 \\
Total Number of Recorded Interactions (I) & 203 & 131 & 188 \\
Connectance (C) & 0.08 & 0.20 & 0.15 \\
Web Asymmetry (W) & 0.31 & 0.48 & 0.42 \\
Mean Links per Pollinator (SD) & $2.94(2.04)$ & $3.04(2.28)$ & $3.47(2.93)$ \\
Mean Links per Plant (SD) & $5.64(6.53)$ & $8.73(5.1 \mathrm{I})$ & $8.17(6.07)$ \\
\hline
\end{tabular}

sites. In the pristine site over half of all interactions (55\%) were Hymenoptera, a noticeably higher proportion in comparison to the late (37\%) and early successional (20\%) sites. Of all Hymenoptera interactions, the proportion of Cape Honey Bee (Apis mellifera capensis) visits were distinctly lower at the pristine site (9\%) compared to the late (37\%) and early successional (43\%) sites. Lepidoptera and Avian interactions were a consistently low proportion of total visits at all three sites (Appendix i).

With regard to network indices (Tab. 2 and 3), the pristine site recorded lower nestedness, connectance, and mean number of links per species compared to the late successional site. Indices for the early successional site fell between the two. The exception to this pattern was mean links per pollinator where early successional site values were higher than those calculated for the late successional site. For nestedness and connectance, values for the early successional site tended to be closer to those of the pristine site; however, for mean numbers of link per plant species values for late and early successional sites were similar. The opposite was true for network specialisation $\left(H^{\prime}\right)$ where the highest values were recorded for the pristine site, and the lowest for the late successional site. For mean species specialization (d'), both plants and pollinators had higher values than those calculated for the late and early successional sites; however, for this index the latter two sites had equivalent values. All calculated indices were significantly different when compared to the generated null models $(\mathrm{P}<0.00 \mathrm{I})$.

Of the six plant species found in all three sites, specialization ( $d$ ') was found to be significantly higher in the pristine site compared to the early successional site (Fig. 4A). This difference was not evident when comparing the mean links per species for these six plant species (Fig. 4B). Specialization (d') (Fig. 5A), and mean links per species (Fig. $5 \mathrm{~B}$ ), of the 16 pollinator species found in all three sites were not found to be significantly different. In terms of pollinator 
TABLE 3: Quantitative pollination network indices for the three study sites

\begin{tabular}{lrrr}
\hline & Pristine & Late Successional & Early Successional \\
\hline WeightedNODF & $\mathrm{I} 2.32$ & $\mathrm{I} 9.53$ & $\mathrm{I} 7.50$ \\
Weighted Connectance & 0.04 & 0.09 & 0.07 \\
Interaction Evenness & 0.59 & 0.63 & 0.62 \\
Shannon Diversity & 4.63 & 4.10 & 4.42 \\
H2 & 0.66 & 0.49 & 0.55 \\
Mean d' Pollinator (SD) & $0.4 \mathrm{I}(0.25)$ & $0.34(0.17)$ & $0.34(0.20)$ \\
Mean d' Plant (SD) & $0.62(0.15)$ & $0.46(0.12)$ & $0.46(0.23)$ \\
\hline
\end{tabular}
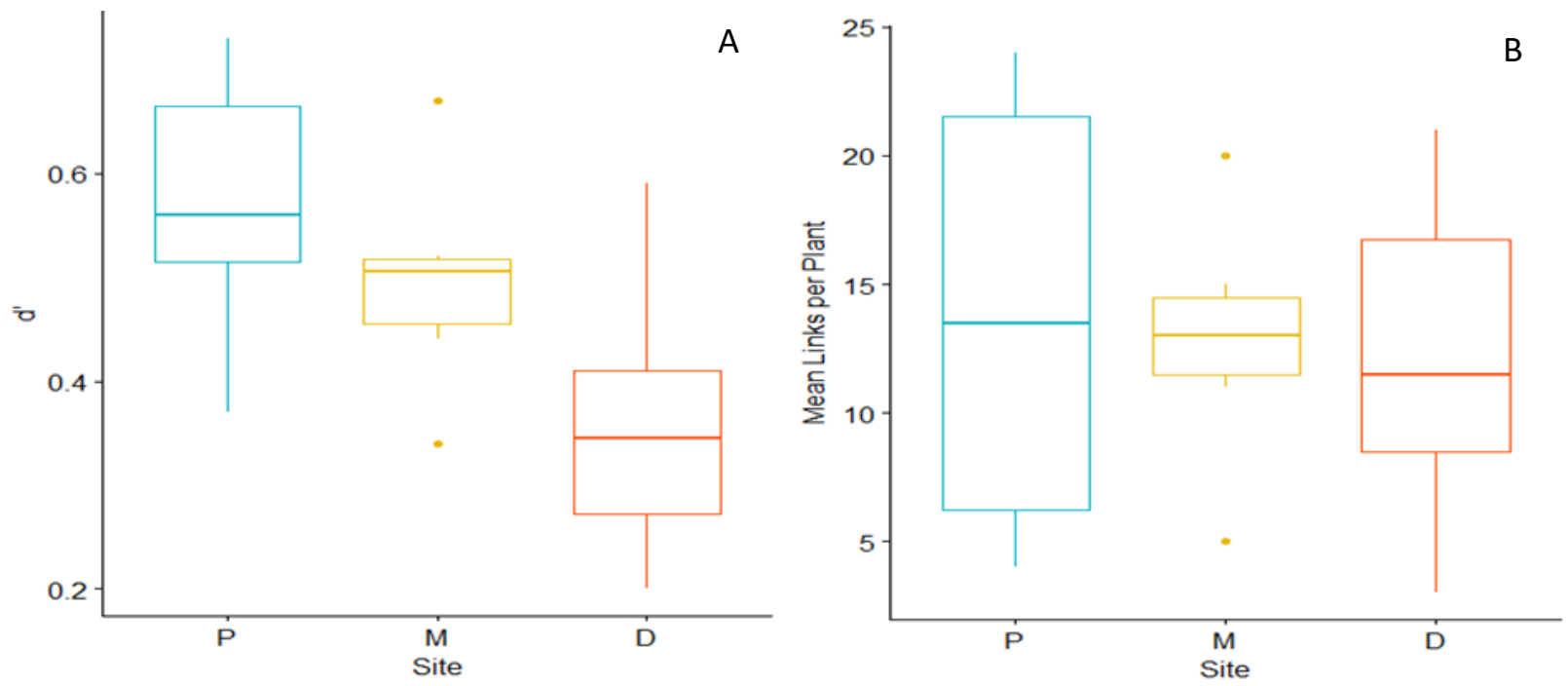

FIGURE 4: Box plots for (A) species-level specialization values (d'), and (B) mean links per plant for the six plant species found in all three sites. $\mathrm{P}=$ Pristine; $\mathrm{M}=$ Late Successional; $\mathrm{D}=$ Early Successional. $\mathrm{P}$ and $\mathrm{D}$ are significantly different at $P<0.05$ in (A).
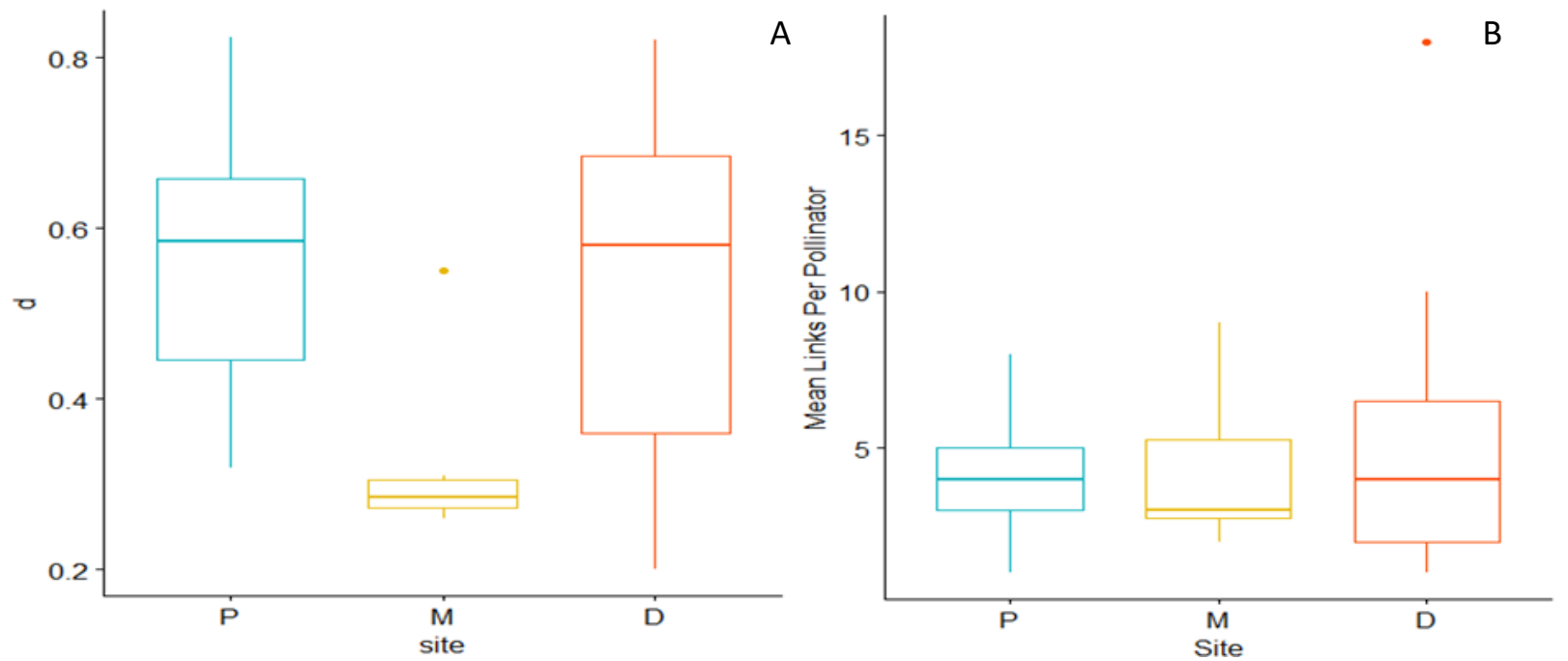

FIGURE 5: Box plots for (A) species-level specialization values (d'), and (B) mean links per pollinator for the I6 pollinator species found in all three sites. $\mathrm{P}=$ Pristine; $\mathrm{M}=$ Late Successional; $\mathrm{D}=$ Early Successional. No significant differences were found. 


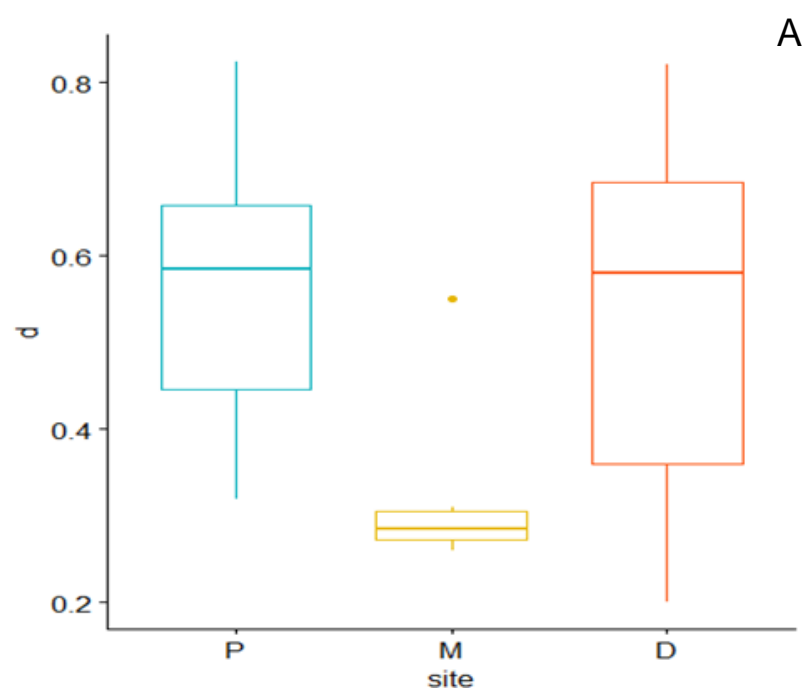

A

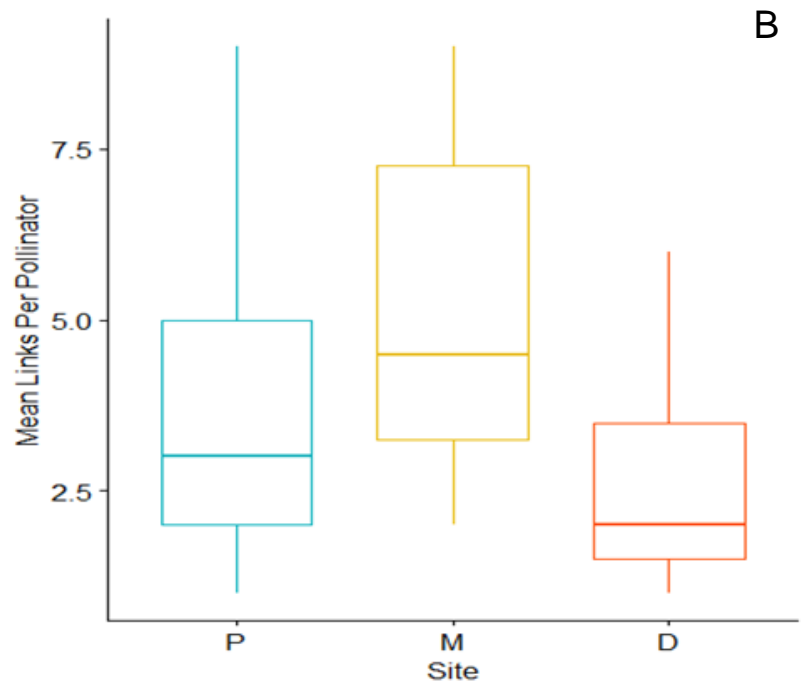

FigurE 6: Box plot showing (A) species-level specialization (d'), and (B) mean links per pollinator for Hymenopteran pollinators between the three sites. $\mathrm{P}=$ Pristine; $\mathrm{M}=$ Late Successional; $\mathrm{D}=$ Early Successional. $\mathrm{P}$ is significantly different to $\mathrm{M}$ at $P<0.00 \mathrm{I}$.

groups, Hymenoptera were significantly more specialized (d') in the pristine site compared to the late successional site (Fig. 6A). No significant difference was found for Hymenoptera mean links per pollinator across sites (Fig. 6B) or d' values and mean links per species for the other pollinator groupings across sites (results not shown).

It is worth re-iterating that due to the nature of this study we were precluded from replicating successional stages. Thus, apart from comparisons between d' values and mean links per plant and pollinators, no statistically robust comparisons between sites was possible. Nevertheless, indices calculated here are suitable for answering our research questions and allow for comparison with datasets from other studies. Moreover, Renosterveld is fragmented vegetation type facing a conservation crisis and furthering our understanding of the role vegetation state and structure play in pollination dynamics is a worthwhile task.

\section{DISCUSSION}

This study presents three complete plant-pollinator networks along a successional gradient in a highly disturbed, critically endangered vegetation type and adds to the scarce data on community-level pollination in Southern Africa and the mainland African continent in general. Here, we discuss the characteristics of the networks as expressed through network indices; how the indices from pristine vegetation compare to i) a similar study conducted in the region and ii) global pollination networks; and, finally, how vegetation change, as a result of initial disturbance followed by secondary succession, is related to i) the richness, evenness and diversity of interactions and ii) the degree of specialization of interactions.

The low connectance value reported for the pristine vegetation pollinator network is typical of large networks (Olesen \& Jordano 2002). The large number of unobserved links may be the result of under-sampling. However, it is more likely the result of forbidden interactions due to species possessing certain traits resulting in phenotypic specialization (Ollerton et al. 2007), or size thresholds between interacting pairs (Stang et al. 2009), which restrict pairwise interactions (Kaiser-Bunbury et al. 20I4). This theoretical network specialization is consistent with the high $\mathrm{H} 2$ ' value reported from the pristine site. Indeed, in comparison to global specialisation data collated from 58 pollination networks (Schleuning et al. 2012), the pristine site in our study ranks as the second highest. Assessing species-level indices shows a similar trend, particularly for plants, with the mean d'value for plants comparable to the higher values collated by Schleuning et al. (2012). The mean d' value for pollinators was less noticeably specialized although still positioned in the upper half when compared to Schleuning et al.'s (2012) dataset. Conversely, compared to the aforementioned dataset (Schleuning et al. 2012), the average number of links per plant is relatively high which would appear to indicate generalised interactions.

This apparent paradox can be understood by considering the difference between qualitative (average number of links per species) and quantitative indices ( $\mathrm{H} 2$ ' and d'). A plant species may only have a single pollinator species visit it but, if this pollinator is common within the community, the plant species would have a low d'value i.e. a visit from this particular pollinator is not unexpected in comparison to its presence within the community. In contrast, a plant species may have interactions with numerous pollinator species but if these pollinators are not recorded on other plant species the d' value would be high (Pauw \& Stanway 2015). High d' despite relatively low number of visitors per plant species is indicative of functional specialization (Fenster et al. 2004) as floral traits select for pollinator species with complementary traits.

There have been no other comprehensive plant-pollinator network studies performed in pristine Renosterveld for comparison; however Pauw and Stanway (2015) reported unparalleled specialization in a pollination network analysis performed in adjacent Fynbos vegetation despite similarly high mean links per plant species. Whilst a distinct vegetation type, Renosterveld has similar levels of diversity to Fynbos and numerous plant families in common (Bergh et al. 20I4). Pauw and Stanway's (2015) Fynbos site was substantially larger 
than that of our pristine Renosterveld site and considerably more diverse ( 62 plants and 217 pollinators), however both networks are characterized by low connectance and high specialization despite relatively high values of mean links per plant compared to global pollination networks (Schleuning et al. 2012). Increased specialization as indicated by the $\mathrm{H} 2$ and $\mathrm{d}$ ' indices in the Fynbos and pristine Renosterveld networks, supports the notion that pollination networks in the region are functionally specialized in comparison to the majority of global studies - perhaps as a result the relative climatic stability through the Quaternary (Chown et al. 2004) which has allowed specialization to manifest and persist (Pauw \& Stanway 2015).

Although compared to the possible range of values for each of the studied indices the differences among the three networks were generally relatively small, consistent patterns were evident and are worthy of discussion. The pristine site was more diverse, had lower connectance, lower asymmetry, lower nestedness, and higher levels of network-level specialisation compared to the late and early successional sites. Interestingly, indices calculated for the early successional site were closer to those of the pristine site compared to indices from the late successional site. While network characteristics as expressed through indices may be artefacts of sampling intensities (Bluthgen 2010), the sampling intensity at each site was equal which suggests these differences can be attributed to the nature of the above-ground vegetation. The late successional site, while free from agricultural activities for over I5 years and dominated by indigenous vegetation, was fairly homogenous with large stands of the shrub Dicerothamnus rhinocerotis present. While present in healthy Renosterveld vegetation, $D$. rhinocerotis is an early successional species which can dominate degraded veld. It is a drab shrub with inconspicuous, wind-pollinated flowers, and of no use as a floral resource to foraging pollinators. In contrast, the early successional site with its recent agricultural activity was far more open with numerous annual flowering species, both indigenous and alien. The more common shrubs, pocketed throughout the site, included Pteronia and Oederra indigenous Asteraceae species with high densities of yellow flowers. The increased diversity in vegetation structure and availability of flowering species in the site in the earlier stage of secondary succession provides superior habitat and floral resources for pollinator populations. The presence of alien vegetation can be beneficial for indigenous pollinator communities and even benefit native flora (Moragues \& Traveset 2005), however the opposite is also true and affects may change through time with changes in community composition (Morales \& Traveset 2009). A lack of replication across successional states prevents any robust conclusions to be drawn on differences in plant-pollinator network structure; however our results indicate that above ground vegetation characteristics are important drivers. The reduced nestedness and lower connectance in pristine site indicate that plants and pollinators are not as highly linked to each other in comparison to the late and early succession sites. This, combined with the higher level of network specialization observed in the pristine site, suggests that the pristine site is less resilient to future stress as network generalization has been associated with increased robustness to perturbation
(Memmot et al. 2004). It may seem counterintuitive that agricultural activity has resulted in subsequent successional systems that are more resilient to future perturbations; however, this relationship can be explained if one considers what habitat degradation can do to a community. More vulnerable and specialized species may go extinct while resistant, generalized species are favoured due to the possession of traits which make them more tolerant to disturbance (Vinebrooke et al. 2004; Redhead et al. 2018). A similar trend was observed in a landscape-level study in Great Britain where agricultural land-cover was positively correlated with generalization and robustness to extinction (Redhead et al. 2018).

At the species level, significant differences were found (i) in specialization (d') between study sites for plant species which were found at all three sites, and (ii) between certain pollinator groups. Four of the six shared plants were Asteraceae shrubs with solitary Scrophulariaceae and Aizoaceae species, and the mean d' values were only significantly higher in the pristine compared to the early successional site with no significant difference in mean d' found between these shared species elsewhere. This implies that in the pristine site, these plant species are attracting a more select number of pollinators compared to the same species in the early successional and late successional sites. Whether this is a sampling artefact due to the increase in pollinator species present in the pristine site or evidence of niche partitioning is hard to say. The fact that six of the species are Asteraceae shrubs with floral traits which do not discriminate against pollinator functional groups would suggest the former, as does the lack of significant differences in mean links per plant.

The only significant difference found in species-level specialization of species across pollinator orders between the sites was a higher mean d' value for Hymenoptera in the pristine site, compared to the late successional site. A quarter of all pollinator species recorded in the pristine site were Hymenoptera many of which were found on a select number of plant species. Conversely, less than $15 \%$ of pollinator species recorded in the late successional site were Hymenoptera, the majority of which visited numerous plant species. The structural heterogeneity of the pristine site may provide more favourable nesting opportunities for a wider array of Hymenoptera (Gess \& Gess 20I4) and the increased floral resources present may additionally allow for greater niche partitioning within Hymenoptera. Steffan-Dewenter and Tscharntke (200I) found that succession of bee (Hymenoptera) communities in fallowed land was related to changes in vegetation. They reported a correlation between both increased species richness of flowering species and increased bee species, and increased cover of flowering plants and bee abundance (Steffan-Dewenter \& Tscharntke 200I).

\section{Conclusion}

Despite a lack of site replication precluding in depth statistical analysis on network-level indices, this study has provided the first insights into plant-pollinator networks within critically endangered Renosterveld vegetation. Similar to a network described by Pauw and Stanway (2015) from the adjacent Fynbos vegetation, Renosterveld pollination 
networks appear highly specialized when compared to global network studies - potentially as a result of climatic stability through the Quaternary which has allowed functional specialization to manifest and persist. In a region vastly transformed by agriculture, variation in above-ground vegetation composition due to habitat alteration and subsequent secondary succession has resulted in changes to pollination network structure. In this study, the late successional site was less diverse, with network indices more dissimilar to that of the pristine site, when compared to the indices of the early successional site. This was probably the result of the dominance of the wind pollinated shrub, $D$. rhinocerotis, at the late trajectory site reducing floral resources and homogenizing vegetation structure. The trajectory of secondary succession in Renosterveld is not necessarily fixed however, with historical land-use activities (e.g. ploughing) and disturbance events post initiation of secondary succession (e.g. fire season, grazing intensity) affecting vegetation dynamics. With regards to pollination, it does appear that more diverse vegetation, both in terms of floral resources and structure, result in more diverse and specialized plantpollinator interaction networks. Although further studies are required, acknowledging this in future management decisions may aid the safeguarding of a crucial ecosystem service in a critically endangered vegetation type.

\section{ACKNOWLEDGEMENTS}

Overberg Renosterveld Conservation Trust for providing access and accommodation at Haarwegskloof; the reserve manager, Jannie Groenewald, for assistance with identifying plant species and expert local knowledge; Prof. J. Ollerton for helpful feedback; Prof. M. Stang and Prof. J. Thomson, and Prof. A. Pauw for helpful comments on an initial manuscript.

Funding - The project was partially funded by the WWF-SA Table Mountain Fund (TM2502), Fynbos Forum Innovation Scholarship, and the National Research Foundation.

Author contributions - O.C. and P.A. designed the project. O.C. collected data, performed analysis and wrote up the paper.

\section{APPENDICES}

Additional supporting information may be found in the online version of this article:

APPENDIX I. Complete plant-pollinator networks from the three study sites.

\section{REFERENCES}

Albrecht M, Riesen M, Schmid B (2010) Plant-pollinator network assembly along the chronosequence of a glacier foreland. Oikos I19: 1610-I624.

Almeida-Neto M, Ulrich W (20II) A straightforward computational approach for measuring nestedness using quantitative matrices. Environmental Modelling and Software 26:173-178.

Arnold SEJ, Le Comber CS, Chittka L (2009) Floer color phenology in European grassland and woodland habitats, through the eyes of pollinators. Israel Journal of Plant Sciences 57: 2I I-230.

Bartomeus I, Vila M, Santamaria L (2008) Contrasting effects of invasive plants in plant-pollinator networks. Oecologia I55: 76I770
Bascompte J (2009) Mutualistic networks. Frontiers in Ecology and the Environment 7:429-436.

Bascompte J, Jordano P, Olesen JM (2006) Asymmetric coevolutionary networks facilitate biodiversity maintenance. Science 3I2:43I-433.

Bergh NG, Verboom GA, Rouget M, Cowling RM (2014) Vegetation types of the Greater Cape Floristic Region. In: Allsopp N, Colville JF, Verboom GA (eds) Fynbos: ecology, evolution, and conservation of a megadiverse region. Oxford University Press, Cape Town, pp 26-46.

Blüthgen N (2010) Why network analysis is often disconnected from community ecology: a critique and an ecologist's guide. Basic and Applied Ecology II: 185-195

Blüthgen N, Menzel F, Blüthgen N (2006) Measuring specialisation in species interaction networks. BMC Ecology 6:9.

Blüthgen N, Frund J, Vazquez DP, Menzel F(2008) What do interaction network metrics tell us about specializationand biological traits. Ecology 89: 3387-3399.

Brown MJ, Paxton RJ (2009) The conservation of bees: a global perspective. Apidologie 40:4I0-4I6.

Brown J, York A, Christie F, McCarthy M (2017) Effects of fire on pollinators and pollination. Journal of Applied Ecology 54: 3I3322.

Bukovac Z, Shrestha M, Garcia JE, Burd M, Dorin A, Dyer AG (2017) Why background colour matters to bees and flowers. Journal of Comparative Physiology 203: 369-380.

Caradonna PJ, Petry WK, Brennan RM, Cunningham JL, Bronstein JL, Waser NM, Sanders NJ (2017) Interaction rewiring and the rapid turnover of plant-pollinator networks. Ecology Letters 20: 385-394.

Chacoff NP, Vazquez DP, Lomascolo SB, Stevani EL, Dorade J, Padron B (2012) Evaluating sampling completeness in a desert plant-pollinator network. Journal of Animal Ecology 8I: 190-200.

Chown SL, Sinclair BJ, Leinaas HP, Gaston KJ (2004) Hemispheric asymmetries in biodiversity - a serious matter for ecology. PLOS Biology 2:1701-1707.

Cornelissen JHC, Lavorel S, Garnier E, Diaz S, Buchmann N, Gurvich DE, Reich PB (2003) A handbook of protocols for standardised and easy measurement of plant functional traits worldwide. Australian Journal of Botany 5I:335-380.

Costanza R, d'Arge R, De Groot R, Farber S, Grasso M, Hannon B, Limburg K (1997) The value of the world's

Donaldson, J. et al. 2002. Effects of habitat fragmentation on pollinator diversity and plant reproductive success in Renosterveld shrublands of South Africa. - Conserv. Biol. I6: I267-I276.

Cowan OS, Anderson PML (20I4) The Peninsula Shale Renosterveld of Devil's Peak, Western Cape: A study into the vegetation and seedbank with a view toward potential restoration. South African Journal of Botany 95:I35-I45.

Curtis O (2013) Management of critically endangered renosterveld fragments in the Overberg, South Africa. PhD dissertation, Department of Botany, University of Cape Town.

Curtis O, Stirton CH, Muasya AM (2013) A conservation and floristic assessment of poorly known species rich quartz-silcrete outcrops within Rûens Shale Renosterveld (Overberg, Western Cape), with taxonomic descriptions of five new species. South African Journal of Botany 87:99-III.

Devoto M, Bailey S, Craze P, Memmott J (2012) Understanding and planning ecological restoration of plant-pollinator networks. Ecology Letters 15:319-328. 
Dormann CF, Frund J, Bluthgen N, Gruber B (2009) Indices, graphs and null models: analysing bipartite ecological networks. The Open Ecology Journal 2:7-24.

Dormann CF, Frund J, Gruber B (2018). The bipartite package. Version 2.I.I. R Project for Statistical Computing, Vienna.

Dupont YL, Padron B, Olesen JM, Petanidou T (2009) Spatiotemporal variation in the structure of pollination networks. Oikos II8:126I-I269

Fenster CB, Armbruster WS, Wilson P, Dudash MR, Thomson JD (2004) Pollination syndromes and floral specialisation. Annual Review of Ecology, Evolution, and Systematics 35:375-403.

Ferreira PA, Boscolo D, Viana BF (2013) What do we know about the effects of landscape change on plant-pollinator interaction networks? Ecological Indicators 3I: 35-40.

Gallai N, Salles JM, Settele J, Vaissiere BE (2009) Economic evaluation of the vulnerability of world agriculture confronted with pollinator decline. Ecological Economics 68:8I0-82I.

Garnier E, Cortez J, Billes G, Navas ML, Roumet C, Debussche M, Laurent G, Blanchard A, Aubry D, Bellmann A, Neill C, Toussaint JP (2004) Plant functional markers capture ecosystem properties during secondary succession. Ecology 85: 2630-2637.

Gess SK, Gess SW (20I4) Wasps and bees in southern Africa. SANBI Biodiversity Series 24. SANBI, Pretoria.

Gibson RH, Knott B, Eberlein T, Memmott J (201I) Sampling method influences the structure of plant-pollinator networks. Oikos I20: 822-83I.

Grass I, JaukerB, Steffan-Dewenter I, Tscharntke T, Jauker F (2018) Past and potential future effects of habitat fragmentation on structure and stability of plant-pollinator and host-parisoid networks. Nature Ecology and Evolution 2: I408-I4I7.

Hallmann CA, Sorg M, Jongejans E, Siepel H, Hofland N, Schwan H, Stenmans W, Muller A, Sumser H, Horren T, Goulson D, de Kroon H (2017) More than 75 percent decline over 27 years in total flying insect biomass in protected areas. PLoS One 12: e0185809. https://doi.org/I0.137I/journal. pone.0185809

Heelemann S, Krug CB, Esler KJ, Reisch C, Poschlod P (2013) Soil seedbanks of remnant and degraded Swartland Shale Renosterveld. Applied Vegetation Science 16:585-597.

Jordano P (1987) Patterns of mutualistic interactions in pollination and seed dispersal: connectance, dependence asymmetries, and coevolution. The American Naturalist 129:657-677.

Jordano P, Bascompte J, Olesen JM (2003) Invariant properties in coevolutionary networks of plant-animal interactions. Ecology Letters 6: 69-8I.

Kaiser-Bunbury CN, Blüthgen N (2015) Integrating network ecology with applied conservation: a synthesis and guide to implementation. AoB Plants 7: [online] URL: doi:I0.1093/aobpla/plv076 (Accessed September 2018).

Kaiser-Bunbury CN, Muff S, Memmott J, Muller CB, Caflisch A (2010) The robustness of pollination networks to the loss of species and interactions: a quantitative approach incorporating pollination behaviour. Ecology Letters I3: 442-452.

Kaiser-Bunbury CN, Vazquez DP, Stang M, Ghazoul J (2014) Determinants of the microstructure of plant-pollinator networks. Ecology 95: 3314-3324.

Kaiser-Bunbury CN, Mougal J, Whittington AE, Valentin T, Gabriel R, Olesen JM, Bluthgen N (2017) Ecosystem restoration strengthens pollination network resilience and function. Nature 542:223.
Kehinde T, Samways MJ (20I4) Insect-flower interactions: network structure in organic versus conventional vineyards. Animal Conservation 17: 40I-409.

Kemper J, Cowling RM, Richardson DM (1999) Fragmentation of South African Renosterveld shrublands: effects on plant community structure and conservation implications. Biological Conservation 90:I03-III.

Kevan PG, Viana BF (2003) The global decline in pollination services. Biodiversity 4:3-8.

Macfadyen S, Gibson R, Polaszek A, Morris RJ, Craze PG, Planque R, Symondson WOC, Memmott J (2009) Do differences in food web structure between organic and conventional farms affect the ecosystem service of pest control? Ecology Letters I2: 229-238.

Memmott J, Waser NM, Price MV (2004) Tolerance of pollination networks to species extinctions. Proceedings of the Royal Society 27I:2605-26II.

Menz MHM, Philips RD, Winfree R, Kremen C, Aizen MA, Johnson SD, Dixon KW (20II) Reconnecting plants and pollinators: challenges in the restoration of pollination mutualisms. Trends in Plant Science I6:4-I2.

Moragues E, Traveset A (2005) Effect of Carpobrotus spp. on the pollination success of native plant species of the Balearic Islands. Biological Conservation I22:61 I-619.

Morales CL, Traveset A (2009) A meta-analysis of impacts of alien vs. native plants on pollinator visitation and reproductive success of co-flowering native plants. Ecological Letters I2:716-728.

Newton IP, Knight RS (2005) The use of a 60-year series of aerial photographs to assess local agricultural transformations of West Coast Renosterveld, an endangered South African vegetation type. South African Geographical Journal 87:18-27.

Olesen JM, Jordano P (2002) Geographic patterns in plantpollinator mutualistic networks. Ecology 83: 2416-2424.

Ollerton J, Killick A, Lamborn E, Watts S, WHiston M (2007) Multiple meanings and modes: on the many ways to be a generalist flower. Taxon 56: 717-728.

Pauw A (2007) Collapse of a pollination web in small conservation areas. Ecology 88:1759-1769.

Pauw A, Hawkins JA (20II) Reconstruction of historical pollination rates reveals linked declines of pollinators and plants. Oikos 120:344-349.

Pauw A, Stanway R (2015) Unrivalled specialisation in a pollination network from South Africa reveals that specialisation increases with latitude only in the Southern Hemisphere. Journal of Biogeography 42:652-66I.

Ponisio LC, Gaiarsa MP, Kremen C (2017) Opportunistic attachment assembles plant-pollinator networks. Ecology Letters 20: I26I-I272.

Potts SG, Vulliamy B, Dafni A, Ne'eman G, O’Toole C, Roberts S, Willmer P (2003) Response of plant-pollinator communities to fire: changes in diversity, abundance and floral reward structure. Oikos IOI: I03-II2.

Potts SG, Biesmeijer JC, Kremen C, Neumann P, Schweiger O, Kunin WE (2010) Global pollinator declines: trends, impacts and drivers. Trends in Ecology and Evolution 25:345-353.

Proulx SR, Promislow DEL, Phillips PC (2005) Network thinking in ecology and evolution. Trends in Ecology and Evolution 20:345-353.

R Core Team. 2013. R: a language and environment for statistical computing. R Foundation for Statistical Computing, Vienna, Austria. http://www.R-project.org/

Rebelo AG, Boucher C, Helme N, Mucina L, Rutherford MR (2006) Fynbos biome. In: Mucina L, Rutherford MR (eds) The 
vegetation of South Africa, Lesotho and Swaziland. South African National Biodiversity Institute, Pretoria, pp I58-259.

Redhead JW, Woodcock BA, Pocock MJ, Pywell RF, Vanbergen AJ, Oliver TH (2018) Potential landscape-scale pollinator networks across Great Britain: structure, stability and influence of agricultural land cover. Ecology Letters [online] URL: https://doi.org/I0.IIII/ele.I3I57 (accessed September 20I8).

Ruwanza S (2017) Towards an integrated ecological restoration approach for abandoned agricultural fields in Renosterveld, South Africa. South African Journal of Science I I3:I-4.

Saavedra S, Stouffer DB, Uzzi B, Bascompte J (2011) Strong contributors to network persistence are the most vulnerable to extinction. Nature 478: 233-235.

Sanchez-Bayo F, Wyckhuys KAG (2019) Worldwide decline of the entomofauna: a review of its drivers. Biological Conservation 232: 8-27.

Schleuning M, Schleuning M, Fründ J, Klein AM, Abrahamczyk S, Alarcón R, Albrecht M, Andersson GK, Bazarian S, Böhning-Gaese K, Bommarco R, Dalsgaard B (2012) Specialisation of mutualistic interaction networks decreases toward tropical latitudes. Current Biology 22:1925-I93I.

Spiesman BJ, Inouye BD (2013) Habitat loss alters the architecture of plant-pollinator networks. Ecology 94: 2688-2696.

Stang M, Klinkhamer PGL, Waser NM, Stang I, van der Meijden E (2009) Size-specific interaction patterns and size matching in a plant-pollintor interaction web. Annals of Botany I03: I459I469.

Steffan-Dewenter I, Tscharntke T (200I) Succession of bee communities on fallows. Ecography 24:83-93.

Stohlgren TJ, Falkner MB, Schell LD (1995) A modified-Whittaker nested vegetation sampling method. Vegetatio II7:II3-I2I.

Tylianakis JM, Tscharntke T, Lewis OT (2007) Habitat modification alters the structure of tropical host-parisitoid food webs. Nature 445:202.
Valdovinos FS, Ramos-Jiliberto R, Flores JD, Espinoza C, Lopez G (2009) Structure and dynamics of pollination networks: the role of alien plants. Oikos I I8: II90-I200.

Valdovinos FS, de Espanes PM, Flores JD, Ramos-Jiliberto R (2013) Adaptive foraging allows the maintenance of biodiversity of pollination networks. Oikos I22: 907-9I7.

Vanbergen AJ, Insect Pollinators Initiative (2013) Threats to an ecosystem service: pressures on pollinators. Frontiers in Ecology and the Environment II:25I-259.

Vanbergen AJ, Woodcock BA, Gray A, Grant F, Telford A, Lambdon P, Chapman DS, Pywell RF, Heard MS, Cavers S (2014) Grazing alters insect visitation networks and plant mating systems. Functional Ecology 28: I78-I89.

Vanbergen AJ, Woodcock BA, Heard MS, Chapman DS (2017) Network size, structure and mutualism dependence affect the propensity for plant-pollinator extinction cascades. Functional Ecology 3I: I285-I293.

Vazquez DP, Chacoff NP, Cagnolo L (2009) Evaluating multiple determinants of the structure of plant-animal mutualistic networks. Ecology 90: 2039-2046.

Villa-Galaviz E, Boege K, del-Val E (20I2) Resilience in plantherbivore networks during secondary succession. PLoS One 7 : https://doi.org/I0.I37I/journal.pone.0053009.

Vinebrooke RD, Cottingham KL, Norberg J, Scheffer M, Dodson SI, Maberly SC, Sommer U (2004) Impacts of multiple stressors on biodiversity and ecosystem functioning: the role of species cotolerance. Oikos I04:45I-457.

Vizentin-Bugoni J, Maruyama PK, de Souza CS, Ollerton J, Rech AR, Sazima M (2018) Plant-pollinator networks in the tropics: a review. In: Datilo W, Rico-Gray V. (eds) Ecological networks in the tropics. Springer, New York pp. 73-9I.

Vorobyev M, Brandt R (1997) How do insect pollinators discriminate colors? Israel Journal of Plant Sciences45: I03-I I3. 